\title{
Cyclooxygenase-2 S-nitrosylation in salivary gland acinar cell inflammatory responses to Porphyromonas gingivalis: modulatory effect of ghrelin
}

\author{
Bronislaw L. Slomiany, Amalia Slomiany
}

University of Medicine and Dentistry of New Jersey, Newark, USA.

Email: slomiabr@umdnj.edu

Received 23 September 2011; revised 30 October 2011; accepted 18 November 2011.

\begin{abstract}
Disturbances in nitric oxide synthase (NOS) system and the excessive prostaglandin $\left(\mathrm{PGE}_{2}\right)$ generation are well-recognized features of oral mucosal inflammatory responses to periodontopathic bacterium, $P$. gingivalis. Employing rat sublingual gland acinar cells, we show that $P$. gingivalis LPS-induced up-regulation in $\mathrm{PGE}_{2}$ generation and the enhancement in inducible (i) iNOS activity was associated with COX-2 activation through S-nitrosylation, and accompanied by the suppression in cSrc activity and the impairment in constitutive (c) cNOS phosphorylation. Further, we demonstrate that the countering effect of peptide hormone, ghrelin, on the LPS-induced changes was reflected in the increased cNOS activation through phosphorylation, repression in iNOS induction, and the reduction in $\mathrm{PGE}_{2}$ generation associated with the loss of COX-2 protein S-nitrosylation. Moreover, the effect of ghrelin on cNOS phosphorylation and the LPS-induced COX-2 S-nitrosylation was susceptible to the blockage by cSrc inhibition. Our findings suggest that $P$. gingivalis-induced up-regulation in iNOS leads to COX-2 S-nitrosylation and up-regulation in $\mathrm{PGE}_{2}$ generation, and that the countering effect of ghrelin is mediated through Src-dependent cNOS activation that is obligatory for the maintenance of iNOS gene suppression.
\end{abstract}

Keywords: Salivary Gland; $P$. gingivalis; iNOS Induction; COX-2 Activation; S-Nitrosylation; Ghrelin; cNOS Phosphorylation

\section{INTRODUCTION}

Porphyromonas gingivalis is a Gram-negative bacterium found in periodontal packets of patients with periodontitis, a chronic destructive inflammatory disease that is a major cause of adult tooth loss [1,2]. The oral mucosal responses to $P$. gingivalis and its key virulence factor, cell-wall lipopolysaccharide (LPS), are characterized by a massive rise in epithelial cell apoptosis and proinflammatory cytokine expression, excessive nitric oxide (NO) generation, and a marked increase in prostaglandin $\left(\mathrm{PGE}_{2}\right)$ production [3-6]. A growing volume of literature, moreover, points towards the existence of a functional and signaling relationship between NO, generated by nitric oxide synthase (NOS) isozyme system, and the formation of $\mathrm{PGE}_{2}$ synthesized from arachidonic acid (AA) by the action of cyclooxygenase (COX) systems [7-11].

Clinical and experimental evidence indicate that physiological and pathophysiological implications of NO and $\mathrm{PGE}_{2}$ depend on the type isozyme system involved in their generation, their subcellular targeting and the local concentration [11-13]. Of the three NOS isozymes responsible for NO generation, the two expressed constitutively (cNOS) are membrane bound and $\mathrm{Ca}^{2+}$-dependent, and provide precise pulses of NO for a fine modulation of the cellular processes that are of importance to the maintenance of normal physiological functions $[8,12$, 14]. The third, inducible isoform (iNOS) is $\mathrm{Ca}^{2+}$-independent, and its cytosolic expression undergoes induction in response to proinflammatory cytokines and bacterial LPS to provide the high output of NO for host defense. However, sustained iNOS activation associated with persistence of inflammatory stimulus is also known to have cytotoxic consequences, causing transcriptional disturbances and the induction of apoptosis $[8,12,15,16]$. The conversion of AA to $\mathrm{PGE}_{2}$ is mediated by two COX isozymes, the constitutive isoform or COX-1 and inducible form or COX-2. The COX-1 is responsible for maintaining the normal physiological prostaglandin production required for housekeeping functions, while the induction of COX-2 expression in response to inflammatory stimulus accounts for up-regulation in $\mathrm{PGE}_{2}$ production observed in various inflammatory diseases $[8,11$, $13,17]$. 
The functional implications of the cross-talk between the products of NOS and COX pathways are supported by the studies indicating that stimulation of NO production through iNOS induction leads to COX enzymes activation and up-regulation in $\mathrm{PGE}_{2}$ generation, whereas NOS gene deletion or inhibition of NOS enzymes with pharmacological agents results in a decrease in $\mathrm{PGE}_{2}$ production $[9,10,18,19]$. Moreover, the COX-2 activation and the resulting increase in $\mathrm{PGE}_{2}$ generation has been linked to the enzyme protein S-nitrosylation associated with LPS-induced up-regulation in iNOS expression $[10,18]$. The role of cNOS in the iNOS-dependent COX2 activation has also been suggested [18,20], and we have shown that the disturbances in NO generation elicited in salivary gland acinar cells by $P$. gingivalis LPS are reflected in the massive up-regulation in iNOS activity and the suppression in cNOS activation $[4,6,16]$.

As peptide hormone, ghrelin, initially isolated from the stomach [21], and more recently identified in oral mucosa, saliva and the acinar cells of salivary glands [22], is recognized as an important modulator of oral mucosal inflammatory responses to $P$. gingivalis through the regulation of NOS isozyme system $[6,14,16]$, in this study we investigated the nature of inflammatory changes induced in sublingual salivary gland acinar cells by $P$. gingivalis LPS and the influence of ghrelin on the crosstalk between the NOS and COX systems. Our results revealed that induction of iNOS by the LPS leads to COX-2 activation through S-nitrosylation, and that ghrelin-induced up-regulation in cNOS activation through phosphorylation results in the suppression of iNOS induction and hence prevents the COX-2 activation.

\section{MATERIALS ANS METHODS}

\subsection{Salivary Gland Cell Incubation}

The acinar cells of sublingual salivary gland, collected from freshly dissected rat salivary glands, were suspended in five volumes of ice-cold Dulbecco's modified (Gibco) Eagle's minimal essential medium (DMEM), supplemented with fungizone $(50 \mu \mathrm{g} / \mathrm{ml})$, penicillin $(50 \mathrm{U} / \mathrm{ml})$, streptomycin $(50 \mu \mathrm{g} / \mathrm{ml})$, and $10 \%$ fetal calf serum, and gently dispersed by trituration with a syringe, and settled by centrifugation [16]. After rinsing, the cells were resuspended in the medium to a concentration of $2 \times 10^{7}$ cell $/ \mathrm{ml}$, transferred in $1 \mathrm{ml}$ aliquots to DMEM in culture dishes and incubated under $95 \% \mathrm{O}_{2}-5 \% \mathrm{CO}_{2}$ atmosphere at $37^{\circ} \mathrm{C}$ for $16 \mathrm{~h}$ in the presence of $P$. gingivalis LPS [16]. In the experiments evaluating the effect of ghrelin (rat, Sigma), cNOS inhibitor, L-NAME, iNOS inhibitor, $1400 \mathrm{~W}$, Src inhibitor, PP2, Akt inhibitor, SH-5, NF-kB inhibitor, PPM-18 (Calbiochem), COX-1 inhibitor, SC-560, COX-2 inhibitor, NS-398, and ascorbate (Sigma), the cells were first preincubated for $30 \mathrm{~min}$ with the indicated dose of the agent or vehicle before the addition of the LPS. The viability of cell preparations before and during the experimentation, assessed by Trypan blue dye exclusion assay [23], was greater than 98\%.

\subsection{NO and $P G E_{2}$ Quantification}

NO production in the acinar cells of sublingual salivary gland was determined by measuring the stable NO metabolite, nitrite, accumulation in the culture medium using Griess reaction [24]. A $100 \mu \mathrm{l}$ of spent culture medium was incubated for $10 \mathrm{~min}$ with $0.1 \mathrm{ml}$ of Griess reagent (Sigma) and the absorbance was measured at 570 $\mathrm{nm}$. $\mathrm{PGE}_{2}$ assays were carried out using enzyme-linked immunoassay (Cayman) and $100 \mu \mathrm{l}$ aliquots of the spent medium supernatant, according to the manufacturer's instructions. The amount of $\mathrm{PGE}_{2}$ released into culture medium was determined by measuring the absorbance at $405 \mathrm{~nm}$ [25].

\section{3. cNOS and iNOS Activity Assay}

The activity of cNOS and iNOS enzymes was measured by monitoring the conversion of L- $\left[{ }^{3} \mathrm{H}\right]$ arginine to $\mathrm{L}-\left[{ }^{3} \mathrm{H}\right]$ citrulline using NOS-detect kit (Stratagene). The acinar cells from the control and experimental treatments were homogenized in a sample buffer containing either 10 mM EDTA (for $\mathrm{Ca}^{2+}$-independent iNOS) or $6 \mathrm{mM} \mathrm{CaCl}_{2}$ (for $\mathrm{Ca}^{2+}$-dependent cNOS), and centrifuged [6]. The aliquots of the resulting supernatant were incubated for $30 \mathrm{~min}$ at $25^{\circ} \mathrm{C}$ in the presence of $50 \mu \mathrm{Ci} / \mathrm{ml}$ of L- $\left[{ }^{3} \mathrm{H}\right]$ arginine, $10 \mathrm{mM}$ NAPDH, $5 \mu \mathrm{M}$ tetrahydrobiopterin, and $50 \mathrm{mM}$ Tis-HCl buffer, $\mathrm{pH}$ 7.4, in a final volume of 250 $\mu \mathrm{l}$. Following addition of stop buffer and Dowex-50 W $\left(\mathrm{Na}^{+}\right)$resin, the mixtures were transferred to spin cups, centrifuged and the formed L- $\left[{ }^{3} \mathrm{H}\right]$ citrulline contained in the flow through was quantified by scintillation counting.

\subsection{COX-2 Activity Assay}

For measurements of COX-2 activity, the acinar cells fro the control and various experimental conditions were settled by centrifugation, rinsed with phosphate-buffered saline, and homogenized in $0.3 \mathrm{ml}$ cold sample buffer containing $0.1 \mathrm{M}$ Tris-HCl, $\mathrm{pH} 7.8$, and $1 \mathrm{mM}$ EDTA. Following centrifugation at $12,000 \times \mathrm{g}$ for $10 \mathrm{~min}$, the supernatant was collected and used for the COX-2 activity assay. The COX-2 activity in $40 \mu \mathrm{l}$ aliquots of the supernatant was measured employing COX activity assay kit in the absence and the presence of COX-1 inhibition (SC-560), according to the manufacturer's (Cayman) instruction. The absorbance was read at $590 \mathrm{~nm}$.

\subsection{Src Kinase Activity Assay}

Tyrosine kinase activity of cSrc in sublingual salivary gland acinar cells was measured by using polyE $\mathrm{F}_{4} \mathrm{Y}$ (Sigma) and 
[g- $\left.{ }^{32} \mathrm{P}\right]$ ATP (Amersham) as the substrates [26]. The cells were lysed in lysis buffer (20 mM Tris-HCl, pH 7.4, 150 $\mathrm{mM} \mathrm{NaCl}, 1 \%$ Triton $\mathrm{X}-100,0.5 \%$ sodium deoxycholate, $2 \mathrm{mM}$ EDTA, $1 \mathrm{mM}$ sodium orthovanadate, $1 \mathrm{mM}$ PAF, and $1 \mathrm{mM} \mathrm{NaF}$ ), containing protease inhibitor cocktail (Sigma), at $4^{\circ} \mathrm{C}$ for $30 \mathrm{~min}$, centrifuged at $12,000 \times \mathrm{g}$ for $10 \mathrm{~min}$, and the supernatants were subjected to protein determination using BCA protein assay kit (Pierce). The supernatant samples containing equal total protein content were then immunoprecipitated with anti-Src antibody (Sigma) for $2 \mathrm{~h}$ at $4^{\circ} \mathrm{C}$. Protein $\mathrm{A} / \mathrm{G}$ agarose beads were added for an additional $1 \mathrm{~h}$, and the immune complex was recovered by centrifugation and thoroughly washed with lysis buffer. The agarose beads were then suspended for $30 \mathrm{~min}$ at room temperature in the kinase assay buffer (10 mM Tris-HCl, pH 7.4, $150 \mathrm{mM} \mathrm{NaCl,} 5$ $\mathrm{mM} \mathrm{MgCl}$, $5 \mathrm{mM} \mathrm{MnCl} 2,2 \mathrm{mM}$ EDTA, and $2 \mathrm{mM}$ dithiotreitol), centrifuged, and the supernatants used for the Src activity assay. For this, the samples containing $25 \mu \mathrm{g}$ of the cell homogenate protein in $50 \mu \mathrm{l}$ of Src kinase assay buffer were incubated with $1 \mathrm{mg} / \mathrm{ml}$ of $\operatorname{polyE}_{4} \mathrm{Y}$ and $100 \mathrm{mM}$ ATP containing $10 \mu \mathrm{Ci}$ of $\left[\mathrm{g}-{ }^{32} \mathrm{P}\right] \mathrm{ATP}$, at $30^{\circ} \mathrm{C}$ for $20 \mathrm{~min}$. The reaction was terminated by adding $25 \mu \mathrm{l}$ of $40 \%$ trichloroacetic, the samples were spotted onto phosphocellulose paper, and following thorough washing with $1 \%$ phosphoric acid and then acetone [27], the radioactivity incorporated into polyE $\mathrm{F}_{4} \mathrm{Y}$ was determined by liquid scintillation counting.

\subsection{COX-2 Protein S-Nitrosylation Assay}

Assessment of COX-2 protein S-nitrosylation in the acinar cells of sublingual salivary gland was conducted using a biotin switch procedure for protein S-nitrosylation $[28,29]$. The cells were treated with iNOS inhibitor, 1400 $\mathrm{W}(30 \mu \mathrm{M})$ or ghrelin $(0.6 \mu \mathrm{g} / \mathrm{ml})$, or Src inhibitor, PP2 $(30 \mu \mathrm{M})+$ ghrelin $(0.6 \mu \mathrm{g} / \mathrm{ml})$, and incubated for $16 \mathrm{~h}$ in the presence of $100 \mathrm{ng} / \mathrm{ml}$ of $P$. gingivalis LPS. Following centrifugation at $500 \times \mathrm{g}$ for $5 \mathrm{~min}$, the recovered cells were lysed in $0.2 \mathrm{ml}$ of HEN lysis buffer (250 mM HEPES, $1 \mathrm{mM}$ EDTA, $0.1 \mathrm{mM}$ neocuprin, $\mathrm{pH}$ 7.7), and the unnitrosylated thiol groups were blocked with Smethyl methanethiosulfonate reagent at $50^{\circ} \mathrm{C}$ for $20 \mathrm{~min}$ [29]. The proteins were precipitated with acetone, resuspended in $0.2 \mathrm{ml}$ of HEN buffer containing 1\% SDS, and subjected to targeted nitrothiol group reduction with sodium ascorbate $(100 \mathrm{mM})$. The free thiols were then labeled with biotin and the biotinylated proteins were recovered on streptavidin beads. The formed streptavidin bead-protein complex was washed with neutralization buffer, and the bound proteins were dissociated from streptavidin beads with $50 \mu \mathrm{l}$ of elution buffer $(20 \mathrm{mM}$ HEPES, 100 mM NaCl, 1 mM EDTA, pH 7.7) contain- ing 1\% 2-mercaptoethanol [29]. The obtained proteins were then analyzed by Western blotting.

\subsection{Immunoblotting Analysis}

The acinar cells of sublingual salivary gland from the control and experimental treatments were collected by centrifugation and resuspended for $30 \mathrm{~min}$ in ice-cold lysis buffer (20 mM Tris- $\mathrm{HCl}, \mathrm{pH}$ 7.4, $150 \mathrm{mM} \mathrm{NaCl}$, $10 \%$ glycerol, $1 \%$ Triton X-100, 2 mM EDTA, $1 \mathrm{mM}$ sodium orthovanadate, $4 \mathrm{mM}$ sodium pyrophosphate, 1 $\mathrm{mM}$ PMSF, and $1 \mathrm{mM} \mathrm{NaF}$ ), containing $1 \mu \mathrm{g} / \mathrm{ml}$ leupeptin and $1 \mu \mathrm{g} / \mathrm{ml}$ pepstatin [14]. Following brief sonication, the lysates were centrifuged at $10,000 \mathrm{~g}$ for 10 $\mathrm{min}$, and the supernatants were subjected to protein determination using BCA protein assay kit (Pierce). The samples, including those subjected to biotin switch procedure, were then resuspended in loading buffer, boiled for $5 \mathrm{~min}$, and subjected to SDS-PAGE using $40 \mathrm{\mu g}$ protein/lane. The separated proteins were transferred onto nitrocellulose membranes, blocked for $1 \mathrm{~h}$ with $5 \%$ skim milk in Tris-buffered Tween (20 mM Tris-HCl, pH 7.4, $150 \mathrm{mM} \mathrm{NaCl}, 0.1 \%$ Tween-20), and probed with specific polyclonal rabbit antibodies directed against COX-1, COX-2, and iNOS (Calbiochem). The phosphorylated cNOS (pcNOS) was analyzed using specific antibody (Calbiochem) directed against phopho-cNOS (mouse anti-eNOS, pSer ${ }^{1179}$ ) and following stripping, probed with antibody against total cNOS.

\subsection{Data Analysis}

All experiments were carried out using duplicate sampling, and the results are expressed as means \pm SD. Analysis of variance (ANOVA) and nonparametric KruskalWallis tests were used to determine significance [6]. Any difference detected was evaluated by means of post hoc Bonferroni test, and the significance level was set at $\mathrm{P}<$ 0.05 .

\section{RESULTS}

To examine the influence of periodontopathic bacterium, $P$. gingivalis, on the relationship between up-regulation in prostaglandin generation and the disturbances in NO production, we employed rat sublingual salivary gland acinar cells exposed to $P$. gingivalis key virulence factor, LPS. We found that the LPS-induced massive increase in NO production was associated with a dose-dependent increase in the acinar cell $\mathrm{PGE}_{2}$ generation, which at 100 ng/ml LPS showed an 11.4-fold increase (Figure 1).

Further, we examined the production of $\mathrm{NO}$ and $\mathrm{PGE}_{2}$ in the presence of NOS and COX systems inhibition. For this, the acinar cells prior to the incubation with the LPS were pretreated with cNOS inhibitor, L-NAME and iNOS inhibitor, $1400 \mathrm{~W}$ (Figure 2), or COX-1 inhibitor, 


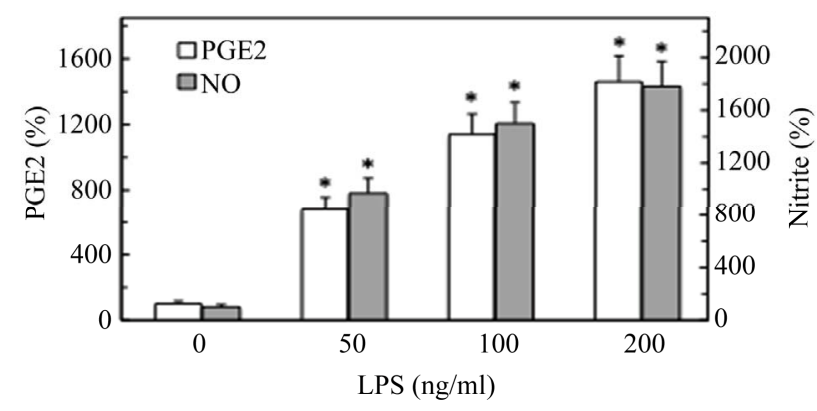

Figure 1. Effect of $P$. gingivalis LPS on $\mathrm{PGE}_{2}$ and nitrite production in rat sublingual salivary gland acinar cells. The acinar cells were treated with the indicated concentrations of the LPS and incubated for $16 \mathrm{~h}$. Values represent the means \pm SD of five experiments. ${ }^{*} \mathrm{P}<0.05$ compared with that of control (LPS $-0)$.

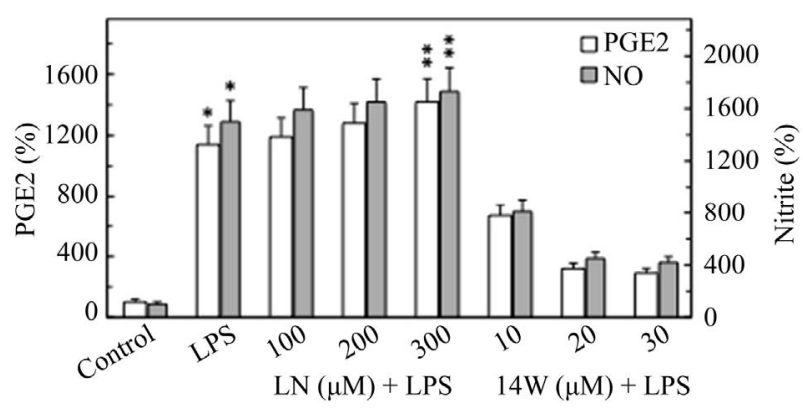

Figure 2. Effect of nitric oxide synthase inhibitors on $P$. gingivalis LPS-induced changes in the production of $\mathrm{PGE}_{2}$ and nitrite by rat sublingual salivary gland acinar cells. The cells, preincubated with the indicated concentrations of cNOS inhibitor, L-NAME (LN), or iNOS inhibitor, $1400 \mathrm{~W}$ (14 W), were treated with the LPS at $100 \mathrm{ng} / \mathrm{ml}$ and incubated for $16 \mathrm{~h}$. Values represent the means \pm SD of five experiments. $* \mathrm{P}<0.05$ compared with that of control. ${ }^{* * \mathrm{P}}<0.5$ compared with that of LPS.

SC-560 and COX-2 inhibitor, NS-398 (Figure 3). The results of assays revealed that the effect of cNOS inhibition was reflected in a moderate increase in the LPSinduced $\mathrm{NO}$ and $\mathrm{PGE}_{2}$, whereas the iNOS inhibitor, 1400 $\mathrm{W}$, elicited a marked reduction in the LPS-induced up-regulation in the acinar cell $\mathrm{NO}$ and $\mathrm{PGE}_{2}$ production. Furthermore, we found that the effect of $P$. gingivalis LPS on the acinar cell capacity for $\mathrm{NO}$ and $\mathrm{PGE}_{2}$ production was not appreciably influenced by COX-1 inhibition with SC-560, while preincubation with COX-2 inhibitor, NS-398, resulted in a marked reduction in $\mathrm{PGE}_{2}$ generation but had no discernible effect on the LPS-induced NO production (Figure 3 ). We also established that the disturbances in NO production elicited in the acinar by $P$. gingivalis LPS were manifested by a massive up-regulation in iNOS activity (Figure 4), whereas the activity of cNOS showed a marked decrease (Figure 5).

Our further results revealed that preincubation of the

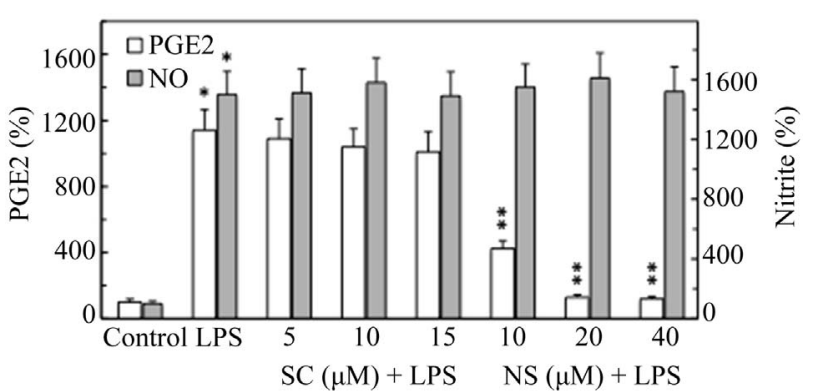

Figure 3. Effect of cyclooxygenase inhibitors on $P$. gingivalis LPS-induced changes in the production of $\mathrm{PGE}_{2}$ and nitrite by the sublingual salivary gland acinar cells. The cells, preincubated with the indicated concentrations of COX-1 inhibitor, SC-560 (SC), or COX-2 inhibitor, NS-398 (NS), were treated with the LPS at $100 \mathrm{ng} / \mathrm{ml}$ and incubated for $16 \mathrm{~h}$. $* \mathrm{P}<0.05$ compared with that of control. ${ }^{* *} \mathrm{P}<0.05$ compared with that of LPS.

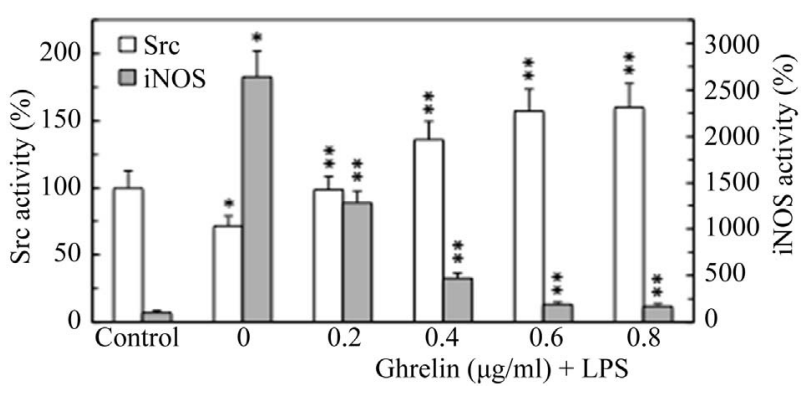

Figure 4. Effect of ghrelin on $P$. gingivalis LPS-induced changes in the expression of Src kinase and iNOS activities in the sublingual salivary gland acinar cells. The cells, preincubated with the indicated concentrations of ghrelin, were treated with the LPS at $100 \mathrm{ng} / \mathrm{ml}$ and incubated for $16 \mathrm{~h}$. Values represent the means \pm SD of five experiments. ${ }^{*} \mathrm{P}<0.05$ compared with that of control. $* * \mathrm{P}<0.05$ compared with that of LPS alone.

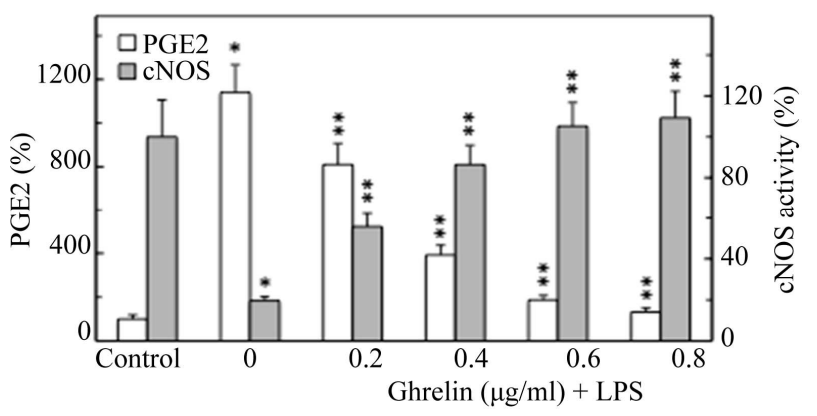

Figure 5. Effect of ghrelin on $P$. gingivalis LPS-induced changes in the production of $\mathrm{PGE}_{2}$ and the expression of cNOS activity in the sublingual salivary gland acinar cells. The cells, preincubated with the indicated concentrations of ghrelin, were treated with the LPS at $100 \mathrm{ng} / \mathrm{ml}$ and incubated for $16 \mathrm{~h}$. Values represent the means $\pm \mathrm{SD}$ of five experiments. $* \mathrm{P}<0.05$ compared with that of control. ${ }^{* *} \mathrm{P}<0.05$ compared with that of LPS alone. 
acinar cells with ghrelin led to a concentration-dependent suppression of the LPS-induced effect on the iNOS activity (Figure 4) and $\mathrm{PGE}_{2}$ generation (Figure 5), while the activity of cNOS showed an increase (Figure 5). As a result, ghrelin at $0.6 \mu \mathrm{g} / \mathrm{ml}$ elicited a 13.9 -fold reduction in the LPS-induced iNOS activity and an $83.7 \%$ drop in the acinar cell $\mathrm{PGE}_{2}$ generation, whereas the activity of cNOS increased by a 5.3-fold (Figure 5). Moreover, the increase in cNOS activation in the presence of ghrelin was associated with a concentration-dependent up-regulation in the acinar cell Src kinase activity, which at $0.6 \mu \mathrm{g} / \mathrm{ml}$ of ghrelin increased 2.2-fold over that of the LPS (Figure 4). Further, as cNOS is known to undergo a rapid posttranslational activation through phosphorylation with the involvement of Src/Akt pathway [6,14], the effect of ghrelin on cNOS phosphorylation at $\operatorname{Ser}^{1179}$ was examined. We observed that that the LPS-induced suppression in cNOS activity was associated with the inhibition in the enzyme phosphorylation, while up-regulation in cNOS activation by ghrelin was reflected in a marked increase in cNOS phosphorylation (Figure 6). Moreover, the suppression of ghrelin effect on cNOS phosphorylation was attained with Src inhibitor, PP2.

To reveal further insight into the relationship between $P$. gingivalis LPS-induced up-regulation in $\mathrm{PGE}_{2}$ generation and iNOS activation, we examined the influence of the LPS and ghrelin on the acinar cell expression of iNOS, and COX-1 and COX-2 proteins (Figure 7). We found that the LPS-induced up-regulation in iNOS activity and $\mathrm{PGE}_{2}$ generation was reflected in the induction in iNOS and COX-2 proteins, while the countering effect of ghrelin was manifested in a marked inhibition of the iNOS protein expression, with no apparent change in COX-2 protein expression. Further, neither the LPS nor ghrelin affected the expression of COX-1 protein. Moreover, NF-кB inhibitor, PPM-18, while causing a marked inhibition in the LPS-induced iNOS protein expression, showed no inhibitory effect on the LPS-induced expression of COX-2 protein (Figure 7). Hence, the enzymatic activity of the LPS-induced COX-2 protein for up-regulation in $\mathrm{PGE}_{2}$ production shows an apparent dependence on NO generated by the iNOS system, and that the countering effect of ghrelin, like that of NF- $\mathrm{KB}$ inhibitor, PPM-18, is the consequence of iNOS enzyme protein suppression.

Accordingly, to provide additional clues as to the requirement of the LPS-induced up-regulation in COX-2 activation for NO, the acinar cells prior to incubation with ghrelin were pretreated with iNOS inhibitor, $1400 \mathrm{~W}$, Src inhibitor, PP2, Akt inhibitor, SH-5, or nitrosothiol reducing agent, ascorbate, and assayed for COX-2 activity. We found that $P$. gingivalis LPS-induced up-regulation in the acinar cell COX-2 activity was subject to

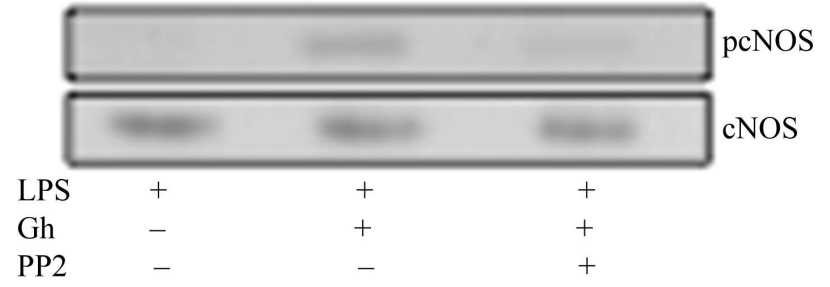

Figure 6. Effect of ghrelin (Gh) and Src kinase inhibitor, PP2, on $P$. gingivalis LPS-induced changes in cNOS phosphorylation in the sublingual salivary gland acinar cells. The cells were treated with Gh at $0.6 \mu \mathrm{g} / \mathrm{ml}$ or Src inhibitor, PP2 at $30 \mu \mathrm{M}+$ Gh, and incubated for $16 \mathrm{~h}$ in the presence of $100 \mathrm{ng} / \mathrm{ml}$ LPS. Cell lysates were resolved on SDS-PAGE, transferred to nitrocellulose and probed with phosphorylation specific cNOS (pcNOS) antibody, and after stripping reprobed with anti-cNOS antibody. The immunoblots shown are representative of three experiments.

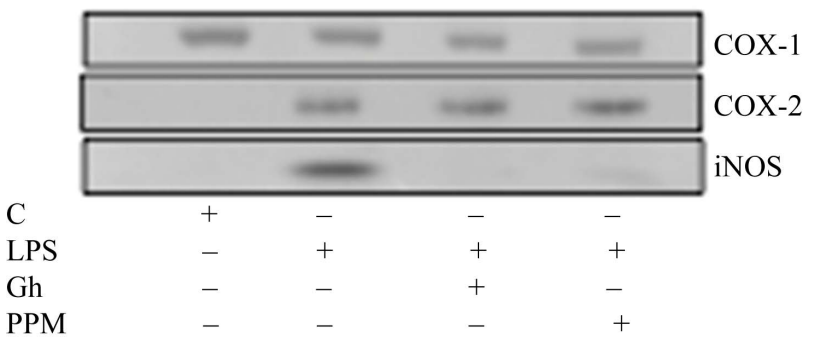

Figure 7. Effect of ghrelin (Gh) on $P$. gingivalis LPS-induced expression of iNOS, and COX-1 and COX-2 proteins in the sublingual salivary gland acinar cells. The cells were treated with the LPS at $100 \mathrm{ng} / \mathrm{ml}$ or ghrelin (Gh) at $0.6 \mu \mathrm{g} / \mathrm{ml}+\mathrm{LPS}$, or NF- $\kappa$ B inhibitor, PPM-18 (PPM) at $15 \mu \mathrm{M}+$ LPS, and incubated for $16 \mathrm{~h}$. Cell lysates were resolved on SDS-PAGE, transferred to nitrocellulose, and probed with anti-iNOS, antiCOX-1, or anti-COX-2 antibody. The immunoblots shown are representative of three experiments.

suppression not only by the pretreatment with ghrelin, but also displayed susceptibility to iNOS inhibitor, 1400 $\mathrm{W}$, while the inhibitors of Src and Akt kinase had no effect (Figure 8). Furthermore, the iNOS inhibitor, 1400 $\mathrm{W}$, produced amplification in the inhibitory effect of ghrelin on COX-2 activity, whereas the inhibitors of Src and Akt, PP2 and SH-5, caused the suppression in ghrelin effectiveness. The LPS-induced COX-2 activation, moreover, displayed susceptibility to suppression by nitrosothiols reducing agent, ascorbate, which produced amplification in the inhibitory effect of ghrelin on COX2 activity (Figure 8). The dependence of COX-2 activation on the LPS-induced up-regulation in iNOS activity was also examined by the biotin switch method [28,29]. The acinar cells were incubated with $P$. gingivalis LPS or ghrelin + LPS in the presence of Src inhibitor, PP2, or iNOS inhibitor, $1400 \mathrm{~W},+$ LPS, and the lysates following the biotin switch procedure were examined for COX- 


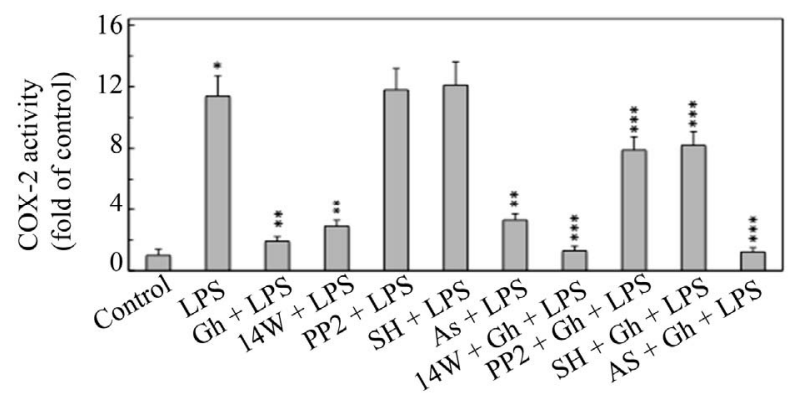

Figure 8. Effect of iNOS inhibitor, $1400 \mathrm{~W}$, Src inhibitor, PP2, Akt inhibitor, SH-5, and ascorbate on the ghrelin (Gh)-induced changes in the expression of COX-2 activity in the sublingual salivary gland acinar cells exposed to $P$. gingivalis LPS. The cells, preincubated with $40 \mu \mathrm{M} 1400 \mathrm{~W}$ (14 W), $30 \mu \mathrm{M}$ PP2, 30 $\mu \mathrm{M}$ SH-5 (SH), or $300 \mu \mathrm{M}$ ascorbate (As), were treated with $\mathrm{Gh}$ at $0.6 \mu \mathrm{g} / \mathrm{ml}$ and incubated for $16 \mathrm{~h}$ in the presence of 100 $\mathrm{ng} / \mathrm{ml}$ LPS. Values represent the means \pm SD of five experiments. $* \mathrm{P}<0.05$ compared with that of control. $* * \mathrm{P}<0.05$ compared with that of LPS alone. $* * * \mathrm{P}<0.05$ compared with that of Gh + LPS.

2 protein S-nitrosylation (Figure 9). We observed that the acinar cells exposed to the LPS alone showed a marked increase in COX-2 protein S-nitrosylation, and that the blockage of iNOS activity with $1400 \mathrm{~W}$, lead to the loss in COX-2 S-nitrosylation. Moreover, substantial loss in the LPS-induced COX-2 S-nitrosylation was also attained in the presence of ghrelin, the effect of which was susceptible to suppression by Src inhibitor, PP2 (Figure 9). Thus, ghrelin countering effects on $P$. gingivalisinduced inflammatory changes are exerted through Srcmediated suppression in iNOS that interferes with COX2 activation through S-nitrosylation.

\section{DISCUSSION}

A Gram-negative bacterium, $P$. gingivalis, is recognized as a major culprit in the development of periodontal disease, a persistent oral mucosal inflammation that that affects $10 \%-15 \%$ of adult population and is the major cause of tooth loss [1,2]. The oral mucosal responses to $P$. gingivalis and its key virulence factor, cell wall LPS, are characterized by a massive rise in epithelial cell apoptosis and proinflammatory cytokine production, disturbances in NO generation, and a marked increase in $\mathrm{PGE}_{2}$ production [3-6,25]. As NO, the product of NOS isozyme system, has been implicated in COX enzyme system activation for the increase in $\mathrm{PGE}_{2}$ production $[9,10,18$, 19], in this study we investigated the influence of $P$. gingivalis LPS on the nature of cross-talk between the NOS and COX systems.

Our findings revealed that the LPS-induced enhancement in sublingual salivary gland acinar cells activity of iNOS and up-regulation in $\mathrm{PGE}_{2}$ generation was accompanied by the suppression in cSrc kinase activity and the

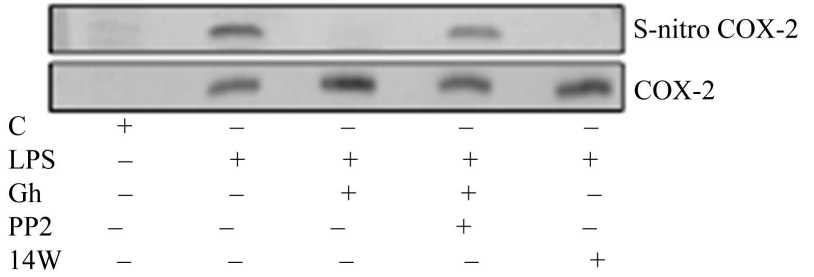

Figure 9. Effect of ghrelin (Gh) on $P$. gingivalis LPS-induced COX-2 S-nitrosylation. The salivary gland acinar cells were treated with Gh $(0.6 \mu \mathrm{g} / \mathrm{ml})$, iNOS inhibitor, $1400 \mathrm{~W}(40 \mu \mathrm{M})$ or Src inhibitor, PP2 $(30 \mu \mathrm{M})+\mathrm{Gh}$, and incubated for $16 \mathrm{~h}$ in the presence of $100 \mathrm{ng} / \mathrm{ml}$ LPS. A portion of the cell lysates was processed by biotin switch procedure for protein S-nitrosylation and, along with the reminder of the lysates, resolved on SDS-PAGE, transferred to nitrocellulose and probed with antiCOX-2 antibody. The immunoblots shown are representative of three experiments.

impairment in cNOS activation through phosphorylation. Moreover, while the stimulatory effect of the LPS on $\mathrm{PGE}_{2}$ production was susceptible to suppression by COX-2 inhibitor, NS-398, as well as the inhibitor of iNOS, $1400 \mathrm{~W}$, the LPS-induced acinar cell NO generation was not affected by the inhibitors of COX-1 and COX-2 system. These findings, thus, support the role of iNOS in the regulation of COX-2 activation and $\mathrm{PGE}_{2}$ generation $[10,18,19]$. Further, preincubation with a peptide hormone, ghrelin, recognized for its modulatory influence on the inflammatory responses to bacterial infection [6,14,22,30,31], elicited countering effect on the LPS-induced suppression in cSrc activity and lead to the increase in cNOS activation through phosphorylation, and the reduction in iNOS protein expression accompanied by the loss in COX-2 activity. Moreover, ghrelininduced up-regulation in cNOS phosphorylation was susceptible to suppression by Src inhibitor, PP2, which also caused the abrogation in ghrelin-induced reduction in COX-2 activity. Thus, it is apparent that ghrelin counters the LPS-induced changes in $\mathrm{PGE}_{2}$ production via $\mathrm{CSrc}$ kinase-mediated cNOS activation through phosphorylation, and that cNOS plays an essential role in the regulation of COX-2 activity by ghrelin. Indeed, the mechanism that underlies the regulation of NO signaling by ghrelin relies on the growth-hormone secretagogue receptor (GHS-R)- mediated activation of G protein-dependent network of protein kinases, including that of membrane-associated non-receptor tyrosine kinase, cSrc [32,33]. Moreover, in concordance with the documented involvement of cSrc in post-translational cNOS activation through phosphorylation [14,16,30,34], we found that the induced up-regulation in cNOS activity by ghrelin was reflected in the increase of enzyme protein phosphorylation at Ser ${ }^{1179}$.

Next, we addressed the relationship between $P$. gingivalis LPS-induced up-regulation in iNOS activity and 
$\mathrm{PGE}_{2}$ generation, and the acinar cell expression of iNOS and COX proteins. While the expression of COX-1 protein remained essentially unaffected by the LPS or ghrelin, the induction in iNOS and COX-2 proteins occurred in the presence of the LPS, whereas the effect of ghrelin was manifested in a marked inhibition of the iNOS protein expression and no apparent change in the expression of COX-2 protein. Further, PPM-18, an NF-kB inhibitor, while causing a marked inhibition in the LPS-induced iNOS expression, did not block the expression of COX-2 protein. Thus, the observed up-regulation in COX-2 activity and $\mathrm{PGE}_{2}$ production shows an apparent dependence on NO generated by the iNOS, and the countering effect of ghrelin is the consequence of iNOS gene repression. In agreement with the prevailing view, it is also evident that whilst the induction of iNOS gene expression in response to LPS involves activation of transcrip-

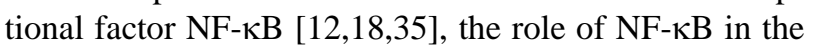
transcriptional control of COX-2 expression is less apparent and remains controversial [17,36,37].

Indeed, depending on cell type, the regulation of COX-2 expression has been attributed to transcriptional factors, NF- $\kappa B$ and AP-1, CREB and CACAT response element binding proteins, as well as kinases of MAPK and PKC family $[17,36,37]$. Moreover, the expression of COX-2 activity has been linked to posttranslational modification of the enzyme protein through S-nitrosylation $[10,18,19]$. Hence, we examined the dependence of $P$. gingivalis LPS-induced acinar cell COX-2 activation on its protein S-nitrosylation. We found that the countering effect of ghrelin on the LPS-induced up-regulation in COX-2 activity was amplified further in the presence of iNOS inhibitor, $1400 \mathrm{~W}$, while the specific inhibitors of Src and Akt caused the suppression of ghrelin effect. Moreover, the LPS-induced COX-2 activation displayed susceptibility to ascorbate, which also produced amplification in the inhibitory effect of ghrelin on COX-2 activation. Thus, taking into consideration the known susceptibility of S-nitrosylated proteins to reduction by ascorbic acid $[10,16,18]$, we assessed the dependence of COX-2 activation on the LPS-induced up-regulation in iNOS activity by the biotin switch procedure [28,29]. Western blot analysis of the acinar cell lysates revealed that the cells exposed to the LPS alone showed a marked increase in COX-2 S-nitrosylation, and that the blockage of iNOS activity with $1400 \mathrm{~W}$, caused the loss in COX-2 S-nitrosylation. Moreover, a substantial drop in the LPS-induced COX-2 S-nitrosylation was also attained in the presence of ghrelin, the effect of which was susceptible to suppression by Src inhibitor, PP2. Collectively, these findings suggest that $P$. gingivalis LPS-elicited induction in iNOS expression leads to COX-2 activation through $\mathrm{S}$-nitrosylation that results in an excessive $\mathrm{PGE}_{2}$ genera- tion, and that the countering effect of ghrelin is mediated via Src/Akt-dependent up-regulation in cNOS activation through phosphorylation that is obligatory for the maintenance of iNOS gene suppression.

Our assertion as to the role of cNOS in the regulation of iNOS gene induction is supported by the literature data indicating that cNOS is capable of affecting transcriptional factor NF- $\mathrm{kB}$ activation, and hence to influence the extent of promoter activity and transcription of iNOS gene $[11,18,20]$. Others have reported that S-nitrosylation of an inhibitor protein IкB kinase complex (IKK) interferes with ubiquitinylation and proteasomal degradation of $\mathrm{I} \kappa \mathrm{B}$, thus preventing the nuclear translocation of NF- $\mathrm{kB}$, and resulting in its inability to promote target gene transcription [38-40]. Finally, we have show herein that $P$. gingivalis LPS-induced suppression in cNOS activation through phosphorylation was manifested the induction in iNOS protein expression, while the countering effect of ghrelin, like that of NF-кB inhibitor, PPM18 , was reflected in the inhibition of iNOS protein expression.

\section{REFERENCES}

[1] Ximenz-Fyvie, L.A., Haffajee, A.D. and Socransky, S. (2000) Micorbial composition of supra- and subgingival plaque in subjects with adult periodontitis. Journal of Clinical Periodontology, 27, 722-732. doi:10.1034/j.1600-051x.2000.027010722.x

[2] Nonnenmacher, C., Mutters, R. and deJacoby, L.F. (2001) Microbiological characteristics of subgingival microbiota in adult periodontitis, localized juvenile periodontitis and rapidly progressive periodontitis subjects. Clinical Microbiology and Infection, 7, 213-221. doi:10.1046/j.1469-0691.2001.00210.x

[3] Wang, P.L. and Ohura, K. (2002) Porphyromonas gingivalis lipopolysaccharide signaling in gingival fibroblastsCD14 and Toll-like receptors. Critical Reviews in Oral Biology and Medicine, 13, 132-142. doi:10.1177/154411130201300204

[4] Slomiany, B.L. and Slomiany, A. (2005) Role of leptin in modulation of Porphyromonas gingivalis lipopolysaccharide-induced up-regulation of endothelin-1 in salivary gland acinar cells. IUBMB Life, 57, 591-595. doi:10.1080/15216540500215598

[5] Slomiany, B.L. and Slomiany, A. (2006) Leptin modulates the detrimental effect of Porphyromonas gingivalis lipopolysaccharide-induced cytosolic phospholipase $\mathrm{A}_{2}$ activation on salivary mucin synthesis via ERK-signal transduction. Inflammopharmacology, 14, 250-255. doi:10.1007/s10787-006-1525-5

[6] Slomiany, B.L. and Slomiany, A. (2010) Suppression by ghrelin of Porphyromonas gingivalis-induced constitutive nitric oxide synthase S-nitrosylation and apoptosis in salivary gland acinar cells. Journal of Signal Transduction, 2010, 643642.

[7] Molace, V., Muscoli, C., Masini, E., Cuzocrea, S. and Salvemini, D. (2005) Modulation of prostaglandin biosynthesis by nitric oxide and nitric oxide donors. Phar- 
macological Reviews, 57, 217-252. doi:10.1124/pr.57.2.1

[8] Cuzzocrea, S. and Salvemini, D. (2007) Molecular mechanisms involved in reciprocal regulation of cyclooxygenase and nitric oxide synthase enzymes. Kidney International, 71, 290-297. doi:10.1038/sj.ki.5002058

[9] Marnett, L.J., Wright, T.L., Crews, B.C., Tannenbaum, S.R. and Morrow, J.D. (2000) Regulation of prostaglandin biosynthesis by nitric oxide is revealed by targeted deletion of inducible nitric-oxide synthase. Journal of Biological Chemistry, 275, 13427-3430. doi:10.1074/jbc.275.18.13427

[10] Kim, S.F., Huri, D.A. and Snyder, S.H. (2005) Inducible nitric oxide synthase binds, S-nitrosylates, and activates cyclooxygenase-2. Science, 310, 1966-1970. doi:10.1126/science.1119407

[11] Tsatsanis, C., Androulidaki, A., Venihaki, M. and Margioris, A.N. (2006) Signaling networks regulating cyclooxygenase-2. International Journal of Biochemistry \& Cell Biology, 38, 2006,1654-1661. doi:10.1016/j.biocel.2006.03.021

[12] Korhonen, R., Lahti, A., Kankaanranta, H. and Moilanen, E. (2005) Nitric oxide production and signaling in inflammation. Current Drug Targets: Inflammation \& Allergy, 4, 471-479. doi:10.2174/1568010054526359

[13] Skill, N.J., Theodorakis, N.G., Wang, Y.N., Wu, J.M., Redmond, E.M. and Sitzmann, J. (2008) Role of cyclooxygenase isoforms in prostacyclin biosynthesis and murine prehepatic portal hypertension. American Journal of PhysiologyGastrointestinal and liver Physiology, 295, G953-964. doi:10.1152/ajpgi.00013.2008

[14] Slomiany, B.L. and Slomiany, A. (2010) Constitutive nitric oxide synthase-mediated caspase-3 S-nitrosylation in ghrelin protection against Porphyromonas gingivalisinduced salivary gland acinar cell apoptosis. Inflammopharmacology, 18, 119-125. doi:10.1007/s10787-010-0035-7

[15] Ma, M.C., Chang, M.Y., Chen, Y.T., et al. (2008) Requirement of inducible nitric-oxide synthase in lipopolysaccharide-mediated Src induction and macrophage migration. Journal of Biological Chemistry, 283, 31408-31416. doi:10.1074/jbc.M801158200

[16] Slomiany, B.L. and Slomiany, A. (2010) Role of ghrelin in modulation of S-nitrosylation-dependent Akt inactivation induced in salivary gland acinar cells by Porphyromonas gingivalis. Health, 2, 2010, 1448-1455. doi:10.4236/health.2010.212215

[17] Joo, M., J.G. Wright, J.G., Hu, N.N., et al. (2007) Yin yang 1 enhances cyclooxygenease- 2 gene expression in macrophages. American Journal of Physiology Lung and Cell Molecular Physiology, 292, L1219-1226. doi:10.1152/ajplung.00474.2006

[18] Ye, Y., Martinez, J.D., Perez-Polo, R.J., Lin, Y., Uretsky, B.F. and Brinbaum, Y. (2008)The role of eNOS, iNOS, and NF-kB in upregulation and activation of cyclooxygenase-2 and infarct size reduction by atorvastin. American Journal of Physiology Heart and Circulatory Physiology, 295, H343-351. doi:10.1152/ajpheart.01350.2007

[19] Lamon, B.D., Upmacis, R.K., Deeb, R.S., Koyuncu, H. and Hajjar, D. (2010) Inducible nitric oxide synthase gene deletion exaggerates MAPK-mediated cyclooxy- genase-2 induction by inflammatory stimuli. American Journal of Physiology Heart and Circulatory Physiology, 299,
H613-623. doi:10.1152/ajpheart.00144.2010

[20] Bell, R.M., Smith, C.C. and Yellon, D.M. (2002) Nitric oxide as a mediator of delayed pharmacological ( $\mathrm{A}_{1}$ receptor triggered) preconditioning; is eNOS masquerading as iNOS? Cardiovascular Research, 53, 405-413. doi:10.1016/S0008-6363(01)00472-2

[21] Kojima, M., Hosoda, H., Date, Y., Nakazato, M. and Kangawa, K. (1999) Ghrelin is a growth-hormone-releasing acylated peptide from stomach. Nature, 402, 656660. doi:10.1038/45230

[22] Groschl, M., Topf, H.G., Bohlender, J., et al. (2005) Identification of ghrelin in human saliva: Production by the salivary glands and potential role in proliferation of oral keratinocytes. Clinical Chemistry, 51, 997-1006. doi:10.1373/clinchem.2004.040667

[23] Slomiany, B.L. and Slomiany, A. (2003) Activation of peroxisome proliferator-activated receptor $\gamma$ impedes Porphyromonas gingivalis lipopolysaccharide interference with salivary mucin synthesis through phosphatidylinositol 3kinase/ERK pathway. Journal of Physiology and Pharmacology, 54, 3-15.

[24] Green, L.C., Wagner, D.A., Glogowski, J., Skipper, P.L., Wishnok, J.S. and Tannenbaum, S.R. (1982) Analysis of nitrte, nitrite, and $\left[{ }^{15} \mathrm{~N}\right]$ nitrate in biological fluids. Analytical Biochemistry, 126, 131-138. doi:10.1016/0003-2697(82)90118-X

[25] Slomiany, B.L. and Slomiany, A. (2007) Alterations by indomethacin in proinflammatory consequences of Salivary gland cytosolic phospholipase $\mathrm{A}_{2}$ activation by Porphyromonas gingivalis: Role of leptin. Journal of Applied Research, 7,127-136.

[26] Lee, S., Lin, X., Nam, N.H., Parang, K. and Sun, G. (2003) Determination of the substrate-docking site of protein tyrosine kinase c-terminal Src kinase. Proceedings National Academy of Science USA, 100,14707-14712. doi:10.1073/pnas.2534493100

[27] Tamiya, S. and Delamere, N.A. (2005) Studies of tyrosine phosphorylation and Src family tyrosine kinases in the lens epithelium. Investigative Ophthalmology \& Visual Science, 46, 2076-2081. doi:10.1167/iovs.04-1199

[28] Jaffrey, S.R., Erdjument-Bromage, H., Ferris, D., Tempst, P. and Snyder, S.H. (2001) Protein S-nitrosylation: A physiological signal for neuronal nitric acid. Nature Cell Biology, 3, 193-197. doi:10.1038/35055104

[29] Forrester, M.T., Foster, M.W. and Stamler, J.S. (2007) Assessment and application of the biotin switch technique for examining protein S-nitrosylation under conditions of pharmacologically induced oxidative stress. Journal of Biological Chemistry, 282, 13977-13983. doi:10.1074/jbc.M609684200

[30] Xu, X., Jhun, B.S., Ha, C.H. and Jin, Z.G. (2008) Molecular mechanisms of ghrelin-mediated endothelial nitricoxide synthase activation. Endocrinology, 149, 4183-4192. doi:10.1210/en.2008-0255

[31] Waseem, T., Duxbury, M., Ito, H., Ashley, S.W. and M.K. Robinson, M.K. (2008) Exogenous ghrelin modulates release of proinflammatory and anti-inflammatory cytokines in LPS-stimulated macrophages through distinct signaling pathways. Surgery, 143, 334-342. doi:10.1016/j.surg.2007.09.039

[32] Lutrell, D.K. and Lutrell, L.M. (2004) Not so strange bedfellows: G-protein-coupled receptors and Src family 
kinases. Oncogene, 23, 7969-7978. doi:10.1038/sj.onc.1208162

[33] Lodeiro, P., Theodoropoulou, M., Pardo, M., Casanueva, F.F. and Camina, J.P. (2009) c-Src regulates Akt signaling in response to ghrelin via b-arrestin signaling-independent and dependent mechanism. PLoS ONE, 4, e4686. doi:10.1371/journal.pone.0004686

[34] Haynes, M.P., Li, L., Sinha, D., et al. (2003) Src kinase mediates phosphatidylinositol3-kinase/Akt-dependent rapid endothelial nitric-oxide synthase activation by estrogen. Journal of Biological Chemistry, 278, 2118-2123. doi:10.1074/jbc.M210828200

[35] Yu, S.M., Wu, J.F., Lin, T.L. and Kuo, S.C. (1997) Inhibition of nitric oxide synthase expression by PPM-18, a novel anti-inflammatory agent, in vitro and in vivo. Biochemical Journal, 328, 363-369.

[36] Grishin, A.V., Wang, J., Potoka, D.A., et al. (2006) Lipopolysaccharide induces cyclooxygenase-2 in intestinal epithelium via a noncanonical p38 MAPK pathway. Jour- nal of Immunology, 176, 580-588.

[37] Cho, I. and Kim, S.G. (2009) A novel mitogen-activated protein kinase phosphatase- 1 and glucocorticoid receptor (GR) interacting protein-1-dependent combinatorial mechanism of gene transrepression by GR. Molecular Endocrinology, 23, 86-99.

[38] Park, S.K., Lin, H.L. and Murphy, S. (1997) Nitric oxide regulates nitric oxide synthase-2 gene expression by inhibiting NF-kB binding to DNA. Biochemical Journal, 22, 609-613.

[39] Reynaert, N.L., Ckless, K., Korn, S.H., et al. (2004) Nitric oxide represses inhibitory B kinase through S-nitrosylation. Proceedings of the National Academy of Sci-ences of the USA, 101, 8945-8950.

[40] Hess, D.T., Matsumoto, A., Kim, S.O., Marshall, H.E. and Stamler, J.S. (2005) Protein S-nitrosylation: purview and parameters. Nature Reviews/Molecular Cell Biology, 6, 150-166. doi:10.1038/nrm1569 